\title{
The Ultimate Expectation of Distance Support Education: Improving the Quality of Rural Education
}

\author{
Panjing Feng \\ School of Education Science, Nanjing Normal University, Nanjing, China
}

\section{Email address:}

1121695526@qq.com

\section{To cite this article:}

Panjing Feng. The Ultimate Expectation of Distance Support Education: Improving the Quality of Rural Education. Education Journal. Vol. 10, No. 3, 2021, pp. 74-77. doi: 10.11648/j.edu.20211003.11

Received: April 6, 2021; Accepted: May 7, 2021; Published: June 1, 2021

\begin{abstract}
At present, there are still some problems in many remote rural primary schools, such as the shortage of high-quality teacher resources, single curriculum structure and content, and lagging educational information. Under the background of "Internet Plus Education", the development of information technology has greatly promoted the vigorous rise of informal education, and education has gradually entered the information age. At the same time, the gradual popularization of network technology also provided a brand-new opportunity for the development of rural education, and distance support education came into being and developed rapidly. In this study, the Distance Support Education Project of A University was taken as a case, and the data are collected through in-depth interviews with principals and teachers from remote rural primary schools and volunteers from distance support education projects. Based on the analysis of the existing curriculum structure and content of rural primary schools and the interview data, this study attempts to summarize the three types of curriculum that currently exist in distance support education: Assisted courses, Enhanced courses, and Extended courses, and explore a relatively ideal teaching curriculum model to achieve the ultimate expectation of distance support education. Namely, the fundamental purpose of distance support education is not to provide direct assistance to rural schools or rural students, but to find the direction for the independent development of rural schools, to realize the "symbiotic" development of rural schools, rural students, and volunteers from college, thus hoping to truly improve the quality of rural education.
\end{abstract}

Keywords: Rural Education, Rural Primary School, Distance Support Education, Curriculum Form, Symbiotic Development

\section{Introduction}

Rural education is an important cornerstone of rural revitalization and national rejuvenation. [1] Teachers are the key to changing the backward situation of rural education. [2] Only with the progress of rural education can China's education be truly powerful. At present, there are still some serious problems in rural education in China, for example, the shortage of teachers' resources, the lack of material resources and backward information, etc. [3] Rural education is in urgent need of supplementing and improve human resources and material resources. In the meantime, However, there are some problems, such as long distance and low efficiency, whether college students come and go in a hurry, or volunteers' intermittent weekend teaching. [4] Although the volunteers who support education have the enthusiasm and strong desire to actively participate, it is difficult to provide effective and long-term support for education in remote rural areas due to the limitation of time and space. With the support of the national education poverty alleviation policy, "Internet Plus Education" provides a new way of thinking to realize education equity. [5] Distance support education is a new type of education support method that has emerged in this context. This is a kind of educational model that spans time, space and regions. Although distance support education lacks emotional communication between teachers and students, compared with practical teaching, it is a breakthrough in traditional teaching to a certain extent. Distance support education is an effective way to solve the shortage of rural teachers and the lack of curriculum resources and make up for the imbalance of educational resources. It is also a sustainable development path of "Internet + Education + Public Welfare" in China. Through the online teaching software, volunteers from universities can 
offer long-distance teaching to rural primary schools and rural students who lack teachers during the normal semester and build an effective communication bridge between the college students and the children in remote rural areas. [6]

\section{Literature Review}

On the basis of existing research on supporting education in rural areas, the researchers try to summarize the literature. From the perspective of research development trend, we can find that society and academia have changed their attention to supporting education in the following two aspects: First, the change from emphasizing educational feelings to re-summation and reflection. Second, the related concepts and mechanisms are gradually clear from ambiguity. From the research content, the existing research mainly involves three dimensions: supporting the investigation of educational status, supporting the analysis of the educational influence and supporting the construction of educational mechanism. That is to say, the current situation of educational support activities is mainly divided into three aspects: teaching volunteers, teaching forms and teaching objectives. This paper analyzes the influence of teaching activities, and discusses the positive role of teaching activities and the existing problems. In view of this situation, this paper puts forward some suggestions for improving the teaching activities and tries to establish a more perfect teaching mechanism. [7]

On the whole, although the experience of supporting education in practice has been rich. Especially in recent ten years, more and more foundations, non-profit organizations and college students' teams have participated in teaching activities, forming a network of activities supporting each other, but it is undeniable that related academic research is still scarce. The existing researches mainly focus on the macro forms of supporting education and the specific impact of supporting education, and seldom study the specific content of supporting education in depth. As an effective supplementary form of current rural school education, although it is not within the scope of standardized school education system, its curriculum and teaching problems actually affect the growth of rural children and the development of rural education, so it needs further exploration and improvement.

\section{Research Method}

This research adopts a qualitative research method. The researchers selected principals and students of some rural primary schools and volunteers from A university as research objects, interviewed principals of selected rural primary schools and volunteers, observed and recorded the implementation of teaching courses, and tried to analyze and summarize the existing curriculum forms of distance support education.

\section{Finding}

Since the implementation of the new curriculum reform, the curriculum of basic education schools in China has changed significantly in terms of objectives, content and evaluation, and has achieved fruitful results in curriculum research and practice. However, in the process of reform, the development of rural education still lags behind that of the cities, which also makes the curriculum development of rural primary schools face two stages: "from scratch" and "from being excellent".

The traditional view is that supporting education is regarded as the aid to remote and weak schools, but the effect of this way is limited. Distance support education is committed to becoming a platform for multi-party cooperation, and complements online support education and daily teaching. On the one hand, it can help college students realize the integration of professional study, scientific research and voluntary service. On the other hand, rural primary schools should be promoted to make blood by themselves with external support, so that students can obtain better educational resources, teachers can achieve professional development and schools can form characteristic education. At the same time, non-profit organizations and the public get more channels to support the development of rural education.

The researchers compared the types of courses offered by the Distance Teaching Program of A University with the actual requirements of the rural primary schools and found that there are three kinds of courses in the distance support education plan: Assisted courses, Enhanced courses, and Extended courses.

\subsection{Assisted Courses}

As for the assisted courses, this means that some rural primary schools do not even provide the courses stipulated by the state. Therefore, it is necessary to provide basic courses for rural primary schools by teaching volunteers in distance education.

For example, from interviews, it is known that rural primary schools lacked formal or fixed full-time English teachers, and their English teaching level was low. Therefore, volunteers who teach distance English courses lack the support of suitable teaching materials, so they mainly teach more interesting content such as spoken English and the culture of English-speaking country, and pay less attention to the basic knowledge of English, art (or art, music) and comprehensive practical courses prescribed by the state. Volunteer teaching is supposed to be taught by rural primary schools, which is "assistance or assistance" to a certain extent.

\subsection{Enhanced Courses}

Concerning the Enhanced courses, that is, some rural primary schools already offer the courses stipulated by the state, but the time and the quality of the courses can not be guaranteed. There is also a lack of professional teachers, so distance-teaching volunteers need to provide relatively professional course content.

For example, in interviews, it was learned that rural primary schools are short of professional teachers in music, 
art, and even physical education. Although most schools have offered music and art courses according to the national regulations and curriculum standards, most of them can only be taught by Chinese or math teachers, and the teaching contents are mostly limited to simple forms such as playing music and displaying pictures by multimedia, which is difficult to provide sufficient support and guidance for the development of students' quality.

For students, an art course is not only objectively beneficial to all-round development, but also one of the most interesting and ideal courses. Therefore, the demand for distance art courses in rural primary schools has always been the most urgent.

\subsection{Extended Courses}

Regarding the Extended courses, that is to say, the docking rural primary schools have offered courses prescribed by the state, and the course time and quality are guaranteed to a certain extent. Therefore, the volunteers supporting distance education can make use of multimedia resources and urban resources to increase the knowledge reserve of rural students and improve the comprehensive quality of rural children. For example, according to our data collection and investigation, we know that colleges and universities offer network literacy courses, mental health courses, financial courses, Chinese studies courses and science courses on the platform of distance education.

Nowadays, among the three types of courses (Assisted courses, Enhanced courses, and Extended courses), most of them are Assisted courses and Enhanced courses. However, we advocate developing from Assisted courses to Enhanced courses and Extended courses form. The form has developed into the form of Extended courses, and the form of Extended courses, which is considered as a more ideal form of distance teaching course.

\section{Discussion and Conclusion}

\subsection{Hope That Distance Support Education Can Help to Effectively Solve the Dilemma of Rural Education}

From the research results, based on the characteristics of long-term support and stable cooperation with rural schools, distance support education can carry out systematic courses according to the characteristics of rural primary schools and the needs of rural students, so that some courses on the curriculum of rural schools no longer just exist in name.

In teaching activities, the volunteer teams from universities and non-profit organizations have become the "partners" in the development of rural school education. It is not "giving" but "symbiosis" for multiple subjects to participate in curriculum construction in rural schools. [8]

However, it is worth reminding that both non-profit organizations and volunteer teams in colleges and universities still can not avoid the "outsider" perspective when developing distance courses. At the same time, under the mainstream social and cultural background, more knowledge and experience are transferred from the experience of urban life. Although rural schools can put forward suggestions for curriculum improvement and seek support for curriculum construction from outside sources, the fundamental change will still depend on the efforts of the rural schools themselves. The fundamental purpose of distance education is not to cover all the problems in the development of rural schools, but to provide the direction for the independent development of rural schools. Through distance supporting education, a great deal of social innovation experience and curriculum development experience is introduced into the rural areas, which can promote the change and improvement of the curriculum idea, school atmosphere, and teachers' ability. It enables rural schools to base themselves on local reality, find out the problem existing in the school curriculum and students' study, and strive to explore local precious curriculum resources, so as to integrate the actual development of students' curriculum more closely.

Because the fundamental purpose of remote education support is not to cover all the problems faced by the development of rural schools but to provide directions for the development of autonomous "blood-making" rural schools. Draining a large amount of social innovation experience and curriculum development experience into the countryside through teaching support, promoting the change and improvement of the curriculum concept, school atmosphere, and teaching ability of rural schools, and then based on local reality, discovering the problems of the school curriculum and student learning, and being good at exploring the local area Valuable curriculum resources, more closely integrate students' current curriculum development practice.

\subsection{Expect That Distance Support Education Can Assist Rural Students to Achieve Comprehensive Growth}

At present, many students in remote rural primary schools have low motivation for learning. On the other hand, rural primary school teachers do not fully understand students' core literacy, nor can they fully understand the relationship between core literacy and students' comprehensive development. Distance support education has changed the present situation to a certain extent, making modern core literacy take root and sprout in rural schools. College volunteers who carry out distance education are mostly normal students, who have a certain pedagogical knowledge base and teaching ability, and can adhere to the core literacy idea in the teaching process. Based on the three-dimensional goals of teaching (knowledge and skills; Procedures and methods; Emotional attitudes and values), we can promote the all-around development of students as much as possible. Music, fine art, Chinese studies, psychology, health, and safety courses supported by distance education can make up for the deficiency of aesthetic and moral education in rural primary schools, and cultivate students' comprehensive quality with the mutual cooperation of knowledge courses.

At the same time, distance supporting education also helps to cultivate the social and emotional abilities of rural primary school students. Social-emotional ability is an important part 
of children's emotional field. Good social-emotional ability is conducive to enhancing children's sense of belonging and participation in school activities, improving attendance, and enhancing children's ability to resist setbacks. Compared with students in urban areas, students in rural elementary schools have always been in a weak position in terms of social and emotional abilities, and their sense of self-identity, sense of belonging, and peer relationships are relatively weak. Distance supporting education allows volunteers to become companions for rural primary school students. Volunteers exert a subtle influence on rural children through their good mental outlook and standardized behaviors, giving them a kind of "demonstration power". In the teaching process, the volunteers will show positive concern to students, and at the same time adopt more ways of encouraging and appreciating education to teach, and cultivate rural students' self-confidence and self-identity through group cooperation, so that students can cultivate peer friendship in social activities.

\subsection{Desire That Distance Support Education Can Fit the Revitalization Direction of Rural Education in the New Era}

The modernization of education calls for revitalizing the modernization of rural education and developing the modernization of rural teaching. [9] There is still a long way to go in revitalizing rural education. Although the project of distance supporting education has opened a path to promoting education equity in urban and rural areas, it is still a long way to truly promote education equity. That is to say, the current distance supporting education project still has not achieved the desired effect in terms of the standardization of the project content and project form.

The existing connection among "non-profit organizations", "volunteer teams in colleges and universities" and "rural schools" is only a phased docking and communication, that is, the communication between non-profit organizations and rural schools may be limited to the stage of setting up project points, and the communication in the later stage is very few. This leads to some problems in matching the needs of rural schools. The dynamic demand of rural school development is determined to accord to the school's development stage and the current situation. Therefore, it is necessary for "non-profit organizations", "college volunteers" and "rural schools" to consult in time, to make better overall planning and considerations.

At present, most distance support education programs only have online courses and offline summer camps. There are many aspects of students' study and life in school, but if only the curriculum is changed, the impact will be relatively small. If the distance education program can design the corresponding "education support section" for each docking school, such as campus lectures, psychological counseling, etc. Through the online platform, it can infiltrate schools in weak areas in many ways, accompany the growth of students as comprehensively as possible, and help rural schools to supplement their lack of professional resources.

While the distance education project has taken a small step toward promoting educational equity in both urban and rural areas, it is still a long way to promote the equity of education. Only by improving the quality of the distance education project can the original intention of the project be realized. At present, there are still some defects in information technology, teaching staff, teaching content and influence. In the future, it is necessary to further improve technology and teachers, and further develop distance education. [10]

\section{Conflict of Interest Statement}

All the authors do not have any possible conflicts of interest.

\section{References}

[1] The Central Committee of the Communist Party of China and State Council. Opinions on comprehensively promoting rural revitalization and accelerating agricultural and rural modernization.

http://www.moa.gov.cn/xw/zwdt/202102/t20210221_6361863 .htm

[2] Ma, Z. (2015) The main problems and development countermeasures of rural basic education in China in the new period. Reform \& Opening (06): 92-93.

[3] Zhao, D., Chen, Y., \& Zhao, K. (2019) On Education Quality of Small Rural Schools: Realistic Predicament and Improving Paths. Journal of Central China Normal University (Humanities and Social Sciences) 58 (02), 157-167.

[4] Wang, X., Yan, C. (2019) Problems and Countermeasures of Short-Term Supporting Education for College Students. Journal of Shenyang Jianzhu University (Social Science) 21 (05), 520-524.

[5] Ministry of Education of the People's Republic of China. The Education Informatization 2.0 Action Plan [EB/OL]. April 18, 2018.

http://www.moe.gov.cn/srcsite/A16/s3342/201804/t20180425 334188.html

[6] Zhao, H., Li, W., \& Yan, K. (2020) Problems, Causes and Countermeasures of College Students' Network Teaching Support Supported by Cloud Classroom. The Chinese Journal of ICT in Education (04), 13-18.

[7] Gong, L., Chen, X. (2014) Research on the Status Quo of Supporting Education for College Students and Sustainable Development. Continue Education Research (08), 72-75.

[8] Sun, D., Li, Y. (2020) A Probe into Rural Education Revitalization-Based on a Theoretical Investigation into the Symbiosis of Urban-Rural Educational Resources. Educational Research 41 (12), 57-66.

[9] Mu, S. (2015) Chance and Challenge: From Open Education Resource to Open Teaching and Learning Process - Thinking Opportunities and Challenges of Chinese Distance Education in the "Internet + " Era. of Open Online Course from Aspect of Distance Education. China Educational Technology (08), 52-58

[10] Chen, L., Lin, S., \& Zheng, Q. (2016) Opportunities and Challenges of Chinese Distance Education in the "Internet + " Era. Modern Distance Education Research (01): 3-10. 